\title{
The Long-term Economic Implications of Brexit for Scotland:
}

\section{An Interregional Analysis}

\author{
by \\ Gioele Figus* \\ Katerina Lisenkova* \\ Peter McGregor* \\ Graeme Roy* \\ J. Kim Swales*
}

Author's copy

Do not distribute

Corresponding author: Dr. Katerina Lisenkova (k.lisenkova@strath.ac.uk)

*Fraser of Allander Institute, University of Strathclyde

November 2017 


\section{Abstract}

This paper offers a cautionary tale about the economic cost of European disintegration. Scotland provides an interesting twist on that story as somewhere that voted to remain part of the EU, but is now likely to be negatively affected, even though it is less directly exposed to EU trade than the UK. This occurs even if it were to achieve a softer Brexit with continued single market membership to which it aspires. The analysis includes potentially important lessons for the many nations and regions in which there exists pressures to move away from trade liberalisation and towards protectionism.

Keywords: Scotland, Brexit, CGE modelling, trade

JEL: R13, C68, F15 


\section{Introduction}

While the likely economic impact of leaving the EU on the economy currently dominates policy debate in the UK there is also considerable international interest. This applies even beyond the immediate speculation concerning the impact on the UK's EU trading partners. There has been growing discontent with globalisation across many countries and there is a concern that other countries might leave the EU and indeed the initial focus was on the possibility of a Greek exit (Grexit). Furthermore, there are strong nationalist/ populist movements pressing for increased protectionism within the EU and beyond. ${ }^{1}$

Most economists predict that leaving the EU will deliver a direct negative shock to trade, labour mobility and investment in the UK. There remains debate, however, over the scale of these effects and their subsequent impacts on economic activity. There is also a potentially offsetting benefit to the public finances through avoiding the net positive contribution that the UK presently makes to the EU budget. Dhingra et al. (2016a, 2016b, 2017a), Ebell and Warren (2016), HM Treasury (2016a, b), OECD (2016), Oxford Economics (2016) and PWC (2016) predict strongly negative economic effects from leaving the EU, whilst Capital Economics (2016) and Economists for Brexit (2016) give a more positive account.

But any impacts of Brexit are accompanied by substantial uncertainty. Given that this is the first time a major economy has withdrawn from the EU, there is no direct prior information which can be used to measure impacts or guide attempts to mitigate any negative effects. Therefore, in order to aid our understanding of the nature and likely size of different impacts, an ex ante simulation

\footnotetext{
${ }^{1}$ In the US the Trump administration decided not to join the Trans Pacific Partnership and wishes to renegotiate NAFTA.
} 
model provides a valuable aid. However, such a model must be based on rigorous theoretical principles and, in this case, must be multi-sectoral, given that leaving the EU will impact differentially on UK industries, partly, but not wholly, reflecting their EU export and import dependency.

Given the heterogeneity of UK, and indeed EU, regions, there is naturally considerable policy interest in the regional impacts of Brexit. There has been some discussion of the likelihood of effects varying across UK regions, which has been based essentially on spatial differences in EU trade patterns. However, this is an area that is, as yet, under-researched (Cicerone et al, 2017; Dhingra et al. 2017b; Los et al. 2017; Sheffield Political Economy Research Institute, 2016; Springford et al. 2016). In this paper we analyse the likely impact of leaving the EU on Scotland, a NUTS 1 region of the UK. ${ }^{2}$ The Scottish case is of particular interest for a number of reasons.

First, as part of the UK, Scotland suffers, direct, indirect and induced impacts from leaving. Scotland is actually less directly exposed to EU trade than the rest-of-the UK (RUK), but since it is highly integrated with the RUK economy we expect strong indirect and induced geographic spillover effects. This implies that the impacts on both Scotland and RUK should be modelled simultaneously. Scotland is therefore illustrative of many EU regions in that the impact of a national shock from leaving will be transmitted partly through spillover effects from the other regions of the host nation. However, this is an aspect of Brexit that has yet to be explored.

Second, Scotland is the region of the UK with the most extensive devolved fiscal, expenditure and legislative powers. In Scotland, many of the adaptive and mitigating policies that may be needed 
to accompany leaving the EU will have to be taken by the Scottish Parliament. The impact on the Scottish economy therefore needs to be separately modelled.

Third, there is also a related political issue. Scotland voted by a majority of $62 \%$ to $38 \%$ for the UK to stay within the EU, with all 32 council areas backing Remain. ${ }^{3}$ The Scottish First Minister initially reacted to this with a call for a second Independence referendum for Scotland, a request that was denied by the UK Prime Minister. While the pressure for a further referendum is currently in abeyance, if leaving the EU imposes a continuing economic burden on the Scottish economy this could be the trigger for future political disruption.

A final, pragmatic, reason for our focus on Scotland is the quality and availability of regional data; in particular, the existence of official input-output tables. Together with the UK data, this allows us to develop what is the first, as far as we are aware, full interregional CGE analysis of Brexit, albeit only for two regions, Scotland and RUK. ${ }^{4}$

We obtain a number of interesting results. These include substantial negative effects on both Scotland and RUK, with the impact on the latter region being greater, reflecting Scotland's lower exposure to EU trade. Of course, the scale of the effects varies with the precise nature of the post leave situation, with the WTO default - "no deal" or "hard Brexit" - position creating the greatest negative effects. We also confirm that there are strong spillovers to Scotland from the RUK: an explicitly interregional analysis proves essential if the significant biases that would result from a "standalone" assessment of the impact of Brexit on the Scottish economy are to be avoided.

\footnotetext{
${ }^{3}$ The results are reported by the BBC: http://www.bbc.co.uk/news/uk-scotland-scotland-politics-36599102. This reflects a distinct Scottish effect, not reflected in Scotland's age, educational or social make up (Langella and Manning, 2016).

${ }^{4}$ Dhingra et al. (2017b) derive results for all NUTS2 regions of the UK, but they do so by distributing national industry results to regions in accordance with those regions' sectoral employment shares.
} 
Furthermore, while these adverse impacts are mitigated by the reduction in the net fiscal contribution to the EU, they are not, even on the most optimistic estimates, nearly sufficient to offset them. In fact, the fiscal position after leaving the EU is always worse than before because of the lost taxing revenue flowing from reduced economic activity. Nor do our results represent a worst case scenario: if dynamic effects link productivity to the degree of openness or inward investment the scale of the contraction would be exacerbated, as it would be if the pressures for international migration created by Brexit are reflected in actual population movements. Our results also shed doubt on the populist notion that it would be in our interest to erect import barriers in retaliation for any EU-imposed barriers to our exports: this would actually add to the economic bad news.

Overall, we believe that our analysis offers a cautionary tale about the economic cost of European disintegration. Scotland provides an interesting twist on that story as it is negatively affected, even though it is less directly exposed to EU trade than the UK. This occurs even if it were to achieve a softer Brexit with continued single market membership to which it aspires. The analysis includes potentially important lessons for the nations and regions in which there exists pressures to move away from trade liberalisation and towards protectionism.

The rest of the paper is structured as follows. Section 2 summarises the key channels through which leaving the EU may have an impact on the Scottish economy. Section 3 provides a short outline of the modelling framework. Section 4 sets out a range of scenarios that could hold in a post-Brexit world, whilst Section 5 presents the key results. Section 6 concludes.

\section{Assessing the long-term impact of Brexit on the Scottish economy}


Theory suggests that, in general, a retreat from trade liberalisation will have negative effects (e.g. Eaton and Kortum, 2002; Baldwin and Venables, 1995). However, in the case of Brexit net fiscal savings associated with leaving the EU provide a possible countervailing influence. To resolve the uncertainty about the direction and scale of the various channels through which alternative forms of Brexit could impact the economy, it is necessary to use models of the UK economy. ${ }^{5}$

In part because of their multi-sectoral structure, which can accommodate the differential impacts of trade barriers across industries, CGE models have been very widely applied to explore trade issues; although the focus has usually been on the consequences of stimulating, rather than reversing, trade liberalisation (e.g. Baldwin and Venables, 1995). PwC (2016) and Dhingra et al. (2016a, 2017a) provide the first CGE analyses of the impact of Brexit on the UK economy. PwC (2016) uses a flexible, full-employment model that estimates fairly modest GDP effects. Similarly, Dhingra et al. (2016a, 2017a) employ a flexible model of world trade, which is medium-term in orientation given the absence of any treatment of physical capital, and again finds comparatively modest Brexit impacts. We discuss the reasons why our results are different in Section 5.

As we have already noted, in order to identify the regional impacts of leaving the EU we have to deal with likely spatial spillovers. So the direct impacts on Scotland of lower integration with the EU are likely to be compounded by additional indirect and induced effects coming through the impact of Brexit on the RUK economy, given the importance of the RUK market for Scottish exports. Accordingly, it is essential to adopt an explicitly interregional analysis that can capture such spillovers.

\footnotetext{
${ }^{5}$ In fact, as we discuss in Section 4, there are further ambiguities surrounding the system-wide output effects of barriers to imports from the EU. The balance of countervailing effects can only be determined by empirical modelling.
} 
To assess the likely long-run implications of leaving, a helpful start is to look at the degree of trade integration between Scotland and the EU. Table 1 shows the value of Scottish exports to the EU for aggregate Services and Manufacturing, with the figures for the largest sectors within these categories separately identified. ${ }^{6}$

Table 1: Scottish EU Exports by Industry Sector, 2014

\begin{tabular}{lcc}
\hline & Value, f M & $\begin{array}{c}\text { Share of EU exports in total } \\
\text { international exports }\end{array}$ \\
\hline Total EU Exports & $\mathbf{1 1 , 5 6 0}$ & $\mathbf{4 3 \%}$ \\
\hline Manufacturing & $\mathbf{6 , 6 9 5}$ & $\mathbf{4 7 \%}$ \\
Food \& Drink & 1,775 & $37 \%$ \\
Coke, refined petroleum and chemical products & 1,775 & $83 \%$ \\
Machinery and Equipment NEC & 650 & $37 \%$ \\
Rubber \& Plastic Products & 575 & $71 \%$ \\
Computer, electronic and optical products & 555 & $50 \%$ \\
\hline Services & $\mathbf{3 , 8 8 5}$ & $\mathbf{4 0 \%}$ \\
Wholesale \& Retail & 1,095 & $61 \%$ \\
Professional Services & 760 & $32 \%$ \\
Administrative and Support Services & 380 & $30 \%$ \\
Transportation and Storage & 355 & $63 \%$ \\
\hline Other & $\mathbf{9 8 0}$ & $\mathbf{5 7 \%}$ \\
\hline
\end{tabular}

Source: Export Statistics Scotland $(2016)^{7}$

\footnotetext{
${ }^{6}$ EU export data contained here http://www.gov.scot/Topics/Statistics/Browse/Economy/Exports/ESSPublication/ESSAddTables

7 There remain ongoing questions around the quality and completeness of export data for Scotland. We would expect a peripheral region of the UK to perhaps have rather less trade with RUK, and rather more with ROW, than the "average" region of the UK. In fact, the reverse is true; Scotland has significantly greater trade links with RUK and greater links with ROW than we would have expected. See Lecca et al (2015) for discussion. However, the Scottish Export Statistics remain the best source for information on Scottish exports. The need for greater coverage of Scottish trade should be an urgent priority for both the Scottish and UK Governments. FAI is currently involved in an Economic Statistics Centre of Excellence project on improving regional trade data.
} 
This information identifies those sectors that are most directly exposed to any change in the trading relationship with the EU. Many of the sectors with the largest EU exports are in manufacturing - including Food \& Drink - but Scotland also has high levels of EU exports in services, particularly those tied to professions, such as legal services, R\&D activities, education, IT and finance.

Many of these sectors are likely to be potential recipients of some special treatment at UK or Scottish levels. However, the particular concerns of individual industries will vary and will depend on more than simply the size of the industry's exposure to EU trade. Many other characteristics of the sector will be important, including the sensitivity of the sector to adjustments to competitiveness that arise through endogenous changes in the real exchange rate and wage rate.

Examining statistics such as those given in Table 1 is a useful exercise but is only a starting point. What is also needed is an assessment of how wider economic transmission mechanisms will feed through to the Scottish economy. Here a multi-regional CGE analysis is required to determine both the direction and scale of the impacts on both Scotland and RUK. ${ }^{8}$ However, a full interregional model for the UK is precluded by data availability. Our two-region CGE model of Scotland and rUK, allows us to undertake the first UK interregional CGE analysis of Brexit.

Finally, it is important to note that this modelling exercise takes other policies as given. ${ }^{9}$ It is likely that policy will respond in the aftermath of leaving the EU. For example, the UK Government

\footnotetext{
${ }^{8}$ Dhingra et al. (2017b), do provide estimates of impacts on NUTS 2 UK regions, but these are obtained by regionalising the UK results from their world trade model simulations (Dhingra et al.,2016a,2017b). These are unable to capture interregional interactions and spillovers.

${ }^{9}$ For example, we assume that both regional fiscal deficits are maintained at their initial levels.
} 
immediately relaxed its targets for reducing the fiscal deficit and has asserted that advantageous new trade deals with third countries will be possible post-Brexit. Further, it may be that R\&D and other regional competitiveness policies might be pursued. ${ }^{10}$ However, we do not consider the effect of such policy initiatives. Our aim is simply to isolate the system-wide impact of leaving the EU.

\section{Model description}

In order to capture spillover effects between Scotland and the rest of the UK and to minimise aggregation biases, we adopt a Computable General Equilibrium (CGE) model of the UK economy, AMOSRUK. It is effectively a multi-sectoral, multi-regional variant of the disaggregated Layard, Nickell and Jackman model (1991, chapter 6), which incorporates imperfect competition in the regional labour market.

The model includes two endogenous regions - Scotland and RUK - and two exogenous regions the rest of the EU (REU) and the rest of the world (ROW) and it is parameterised on an interregional Social Accounting Matrix (SAM) for Scotland and RUK for 2010.11 There are three transactor groups in each region - households, firms and government - and eighteen productive sectors. ${ }^{12}$

Firms and trade

\footnotetext{
${ }^{10}$ However, the literature on liberalisation would suggest that an adverse effect on R\&D from trade reductions.

${ }^{11}$ The SAM is produced by the Fraser of Allander Institute and can be downloaded from http://www.strath.ac.uk/business/economics/fraserofallanderinstitute/research/economicmodelling/

12 The complete model listing is given in Appendix A.
} 
In each sector, local intermediate inputs are combined with imports from the other region and the rest of the world (EU and non-EU) via an Armington link (Armington, 1969); value added is produced by combination of capital and labour. Intermediate input is then combined with value added to determine the sector's gross output. This is done using a nested CES production function with an elasticity of substitution of 0.3 (Harris, 1989).

The price of imports and the interest rate are both set exogenously in perfectly integrated national/international markets. Regional exports are determined through conventional (Armington) trade function. Non-price determinants of export demand from the rest of the world are taken to be exogenous. Export demand of the other UK region is fully endogenous, depending not only on relative prices, but also on all elements of intermediate and final demand in the other region.

Imports from ROW are disaggregated between imports from non-EU and from EU countries (see Figure 1). This structure is adopted for import of intermediate input as well as for household and investment demand.

Figure 1. Schematic of the nested Armington system

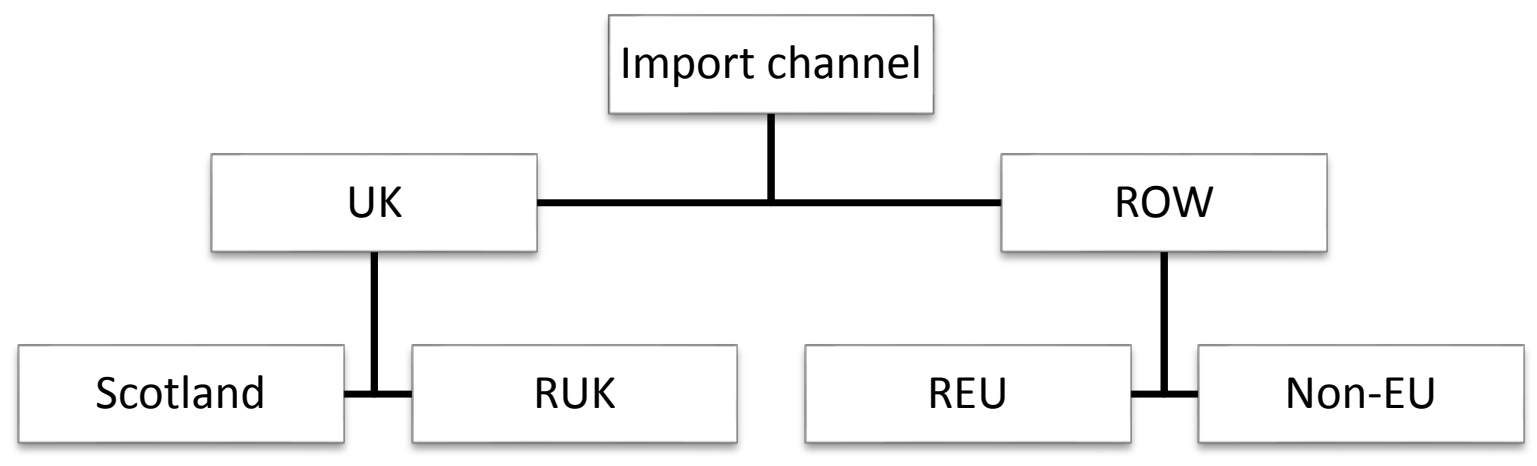


The Armington equation at each level and for each component of demand takes the following standard form:

$$
\frac{D 1_{r, i, t}}{D 2_{r, i, t}}=\left[\left(\frac{\delta_{r, i}^{1}}{\delta_{r, i}^{2}}\right) \cdot\left(\frac{P 2_{r, i,}}{P 1_{r, i, t}}\right)\right]^{\frac{1}{1-\rho_{i}^{A}}}
$$

where $D 1$ and $D 2$ stand for demand for goods and services from two different origins; $P 1$ and $P 2$ stand for respective prices; $\rho^{A}$ is the import elasticity of substitution between output from origins 1 and 2 and is set to 2 (Gibson, 1990); $\delta^{1}$ and $\delta^{2}$ are the shares in the Armington function.

Exports to every destination depend on relative prices and an elasticity of substitution between outputs from different origins. Export equations take the following form:

$$
E 1_{r, i, t}=\overline{E 1}_{i} \cdot\left(\frac{P E 1_{r, i, t}}{P R_{r, i, t}}\right)^{\sigma_{i}^{x}}
$$

where $E 1$ is the volume of exports to destination $1, \overline{E 1}$ is the baseline level of exports to destination 1, PE1 is an exogenous price at destination $1, P R$ is domestic price and $\sigma^{x}$ is export elasticity of substitution between outputs from different origins.

Trade from/to the rest of the world is separated into EU and non-EU regions using the data on export and import patterns from the Trade in Value Added (TiVA) data for the UK and Scottish Export Statistics. Since detailed data on trade partners for imports to Scotland are unavailable we use the UK sectoral proportions to distribute total imports. 
Investment

Investment demand from each sector is a proportion of the difference between actual and desired capital stock (Eq. A.58), where desired capital stock is derived by firm's cost minimisation (Eq. A.59). In the long-run equilibrium actual and desired capital stocks are equal.

\section{Labour market}

Wages are determined within each region using a regional wage curve (Blanchflower and Oswald, 1994) based on the econometrically-parameterised relationship in Layard et al (1991). The effective population constraint applies at the regional level, with regional real wages reflecting the tightness of the regional labour market, measured as inversely related to the regional unemployment rate. In our default simulation it is assumed that there is no international or interregional migration. ${ }^{13}$ Therefore population and potential labour supply in each region remains unchanged during the simulation period.

\section{Government}

We assume that Scotland and RUK maintain a fixed fiscal deficit in the face of the Brexit shocks. Any variation in tax revenues are absorbed by changes in both Governments' current spending. ${ }^{14}$

\footnotetext{
${ }^{13}$ However, we do briefly discuss the importance of migration in Section 4, and report some simulation results allowing for migration in Section 5. For interregional migration we employ the estimated net migration function reported in Layard et al (1991), which relates net migration to real wage and unemployment rate differentials. We also note the limiting case of international migration in the absence of barriers to such movements, which implies fixed real wage rates in both regions. ${ }^{14}$ Of course, this implies that government spending falls in response to a Brexit-induced decline in activity and in tax revenues, exacerbating the contraction. Under the new Fiscal Framework, Scotland's spending is now dependent on its income tax revenues. The UK could alternatively borrow more, but the ultimate direction of effects would be the same.
} 
Appendix A contains a complete model listing.

\section{Scenarios}

We first consider alternative variants of Brexit, and then discuss how these are reflected in our simulations.

\subsection{Alternative variants of Brexit}

Given the uncertainties surrounding leaving the EU, we need to consider alternative futures, reflecting a range of different possible trading relationships. We explicitly model two main effects. These are: the imposition of additional constraints to UK trade with the EU; and the repatriation of fiscal contributions that the UK currently makes to the EU budget. We do not explicitly model the potential migration, FDI and productivity effects identified in the literature because their scale is so uncertain. ${ }^{15,16}$

We model two illustrative leave scenarios for the UK-EU interactions, namely a Free Trade Agreement (FTA) with the EU and the World Trade Organisation (WTO) scenarios. Both of the options involve:

- Stopping or reducing financial contributions to the EU;

- Ending the free movement of people;

- retaining all trade deals between the EU and third countries.

The Free Trade Agreement (FTA) with the EU assumes that:

\footnotetext{
15 We do briefly consider these effects in Figus et al (2017).

${ }^{16}$ For the discussion of the effects of reducing migration to the UK after Brexit see Lisenkova K, Sanchez-Martinez M (2016)
} 
- leaving the Single Market and customs union and therefore being subject to an 'economic border' including 'rules of origin';

- negotiating a free trade agreement with the EU, which will be less comprehensive than membership of the Single Market;

- reduced or no fiscal contributions to the EU.

The World Trade Organisation (WTO) scenario is the default, which would apply if a better deal cannot be secured. This is the "no deal" or "hard Brexit" scenario, which involves:

- falling back to the WTO rules for trade with the EU;

- $\quad$ tariffs on trade with the EU;

- no financial contributions to the EU.

The aim of these scenarios is to provide an illustration of the direction and scale of possible impacts. Each scenario implies a different degree of integration with the EU. All scenarios assume an unchanged policy stance, so that both regions maintain their initial fiscal deficits. Given that public sector revenues typically fall in response to an adverse economic shock, such as that embodied in Brexit, this requires corresponding reductions in government expenditures, which exacerbate the contractionary impact (at least in the absence of the reduction in the net fiscal contribution after leaving the EU).

All simulations presented here are timed from the moment when the agreement on Brexit is implemented; that is from the end of any transitionary adjustment period that may be agreed. We gradually introduce shocks over the first ten periods of the simulations.

\section{Trade shocks}


We use estimates of the impact on UK trade under these two stylised scenarios reported in Ebell (2016). She uses an empirical gravity model and the most recent available data for 42 countries to estimate the effect of membership of the European Economic Area (EEA) ${ }^{17}$ and other, looser, FTAs on trade in goods and services. This methodology is similar to that used by other contributions in the literature and arrives at effects of comparable size (Baier et al, 2008; Ceglowski, 2006; Egger et al, 2011). However, Ebell (2016) uses the most recent data, differentiates trade in goods and services, and explicitly models the effects of EEA membership and other FTAs.

Table 2 provides estimates of the reduction in trade with the EU for goods and services under each scenario. These are substantial18. Due to the way the model was specified in Ebell (2016) with one dummy variable representing the overall effect on bilateral trade, this dummy captures three groups of effects: 1) tariff barriers; 2) non-tariff barriers; and 3) border effects. The first component is often discussed and is easy to describe and understand. In simple terms, after leaving the Single Market the UK might be subject to tariffs. In the WTO case they will be the most favoured nation (MFN) tariffs. They constitute a smaller part of the trade restrictions. In 2014 the trade weighted average tariff applied by the EU was $2.7 \%$ (WTO, 2016)

Table 2: Impact of various post-Brexit scenarios on Scotland's exports

\begin{tabular}{lcc}
\hline & \multicolumn{2}{c}{ Estimated reduction in EU trade } \\
& Goods & Services \\
\hline FTA Scenario & $-40 \%^{19}$ & $-63 \%$ \\
\hline
\end{tabular}

\footnotetext{
1728 countries of the EU plus Iceland, Norway and Liechtenstein

18 The quantitative impact we derive ultimately depends upon the scale and composition of the initial shock. Different studies use different estimates of the possible effect of Brexit on trade. We have tested for a wide range of scenarios and whilst the quantitative impacts change, the qualitative impacts and relative scale of the effects between regions, sectors and transmission channels found here still hold.

${ }^{19}$ We use arithmetic averages of the rage of estimated effects (using different model specifications) from Ebell (2016).
} 


\begin{tabular}{lll}
\hline WTO Scenario & $-61 \%$ & $-63 \%$ \\
\hline
\end{tabular}

Source: Ebell (2016)

Non-tariff barriers represent infrastructure (customs queue and checks), bureaucratic (rules of origin) and regulatory (product standards) restrictions. Non-tariff barriers are usually estimated to be more important than tariff barriers in restricting trade. Non-tariff barriers include the customs controls for goods being exported to the $\mathrm{EU}^{20}$. 'Rules of Origin' require exporters to obtain certificates to demonstrate the domestic content of their exports. The cost of these restrictions can be significant, particularly for smaller firms and businesses that rely on complex cross-border supply chains. Firms trading with the EU have to submit customs declarations and there can be complications with VAT arrangements when products cross borders. This may have implications for costs, efficiency and time competitiveness ${ }^{21}$.

The third component - border effects - is much less well understood. It reflects the observation that regions within a country trade with each other much more that similar regions across countries (e.g. McCallum, 1995; Evans, 2001). These unexplained border effects are usually very large, attributable to unobservable, perhaps psychological, effects and can be extremely difficult to change.

\footnotetext{
${ }^{20}$ The relevant form has more than 50 boxes requesting information, and the guidance is 78 pages long. It typically requires evidence proving products are either made inside the EEA, or comply with a number of product specific rules. For information see - http://eur-lex.europa.eu/legal-ontent/EN/TXT/HTML/?uri=OJ:L:2005:321:FULL\&from=en

${ }^{21} \mathrm{HM}$ Treasure estimate that over half of UK goods exports to the EU would need to be certified as complying with rules of origin requirements in order to continue to receive tariff-free access into the Single Market.
} 
We interpret the reduction in trade associated with looser integration with the EU as a change in explicit (tariffs) and implicit (non-tariff barriers and border effects) prices. All three groups of factors will make it costlier for the UK to trade with the EU (and vice-versa). To introduce these changes into the model we increase the EU import price in the import equation (1), and reduce the EU price in the export equation (2). This implies that imports from the EU are now more expensive in the UK, and UK exports to the EU are less competitive. We calibrate the price shocks to achieve the overall long-run reductions in EU export and import quantities reported in Table 2.

To account for delays in responses to changes in tariff and non-tariff barriers we introduce the shocks gradually over ten years.

We apply universal price shocks across all sectors. However, the resulting trade impacts vary across sectors, depending on each sector's exposure to EU trade through both exports and imports. Overall RUK is more directly exposed to EU trade through both import and export channels. Total EU imports constitute 7\% of total output in Scotland and 9\% in RUK, whilst EU exports make up 4\% of total output in Scotland and 7\% in RUK. Also RUK is a much larger trading partner for Scotland. Both RUK imports and exports comprise $15 \%$ of total Scottish output but Scottish trade makes up only $1 \%$ of RUK output. Not surprisingly, these differences have a significant impact on our simulation results.

\section{Fiscal contributions}

In the Brexit referendum a key element of the debate was the return to the UK of the net fiscal contribution made to the EU, which stood at $f 8.6 \mathrm{bn}$ in 2014 . This takes account of the UK rebate and other receipts, such as those distributed through the CAP and EU structural funds, and assumes that the UK Government replaces all EU expenditures made in the UK. 
We model the positive effects resulting from the reduced EU contribution as higher UK public expenditure (even after maintaining existing EU spending in both Scotland and RUK). The extent of the positive fiscal effects depends upon the negotiated settlement. Both Norway (a member of EEA) and Switzerland (a member of EFTA) make contributions to the EU budget despite not being members of the EU. We consider the UK benefits from the full saving of current net EU contributions. Of course, any realistic settlement under the FTA scenario is likely to be less favourable, but it provides us with an estimate of the maximum fiscal benefits that would be associated with a WTO outcome. Assuming that the fiscal stimulus is allocated to UK regions on a population share basis implies that the Scottish Government's budget increases by $f 690 \mathrm{~m}$ ( $8 \%$ of the total UK contribution) and the RUK budget increases by $f 7.91 \mathrm{bn} .{ }^{22,23}$ Throughout we assume that both the UK and Scottish Governments spend the additional resource. ${ }^{24}$

\subsection{Simulation set-up}

As discussed above, the export and import price shocks that we simulate in AMOSRUK are calibrated to generate, as closely as possible, the trade reductions reported in Table 2 for the FTA and WTO scenarios. A perfect match is difficult to achieve since both import and export volumes are endogenous and influence one another. Also, as we have seen, the two regions have different exposures to trade with the EU and thus react to the same price shock differently. All types of

\footnotetext{
${ }^{22}$ Note that this sharing only applies to the net fiscal saving. Scotland's higher share of agricultural subsidies, for example, is retained given the UK government's commitment to maintaining current EU spending in the UK.

${ }^{23}$ Scotland's share of UK public expenditure in 2015/16 was 9\% (GERS) whilst Scotland's population (2014) and GDP (2015) share was $8 \%$.

${ }^{24}$ We do not explore variations on the fiscal settlement under FTA in detail, since our results prove to be insensitive to such variations.
} 
trade restrictions (tariff and non-tariff barriers and border effects) are expressed in the form of "equivalent" tariffs.

The exogenous price changes that we simulate are reported in Table 3. The size of the shocks vary between exports and imports and between goods and services (and recall that services usually are not included in FTAs), but apply shocks of the same size to Scotland and RUK in each category. The permanent price shocks are introduced gradually over a ten-year period.

Table 3. The permanent import and export price shocks attributable to Brexit under the WTO (FTA) scenarios (\% changes)

\begin{tabular}{|l|c|c|c|}
\hline & Period 1 & Period 5 & Period 10 \\
\hline Export price of goods & $-3.5(-2.2)$ & $-17.5(-11.0)$ & $-35.0(-22.0)$ \\
\hline Export price of services & $-4.0(-4.0)$ & $-20.0(-20.0)$ & $-40.0(-40.0)$ \\
\hline Import price of goods & $7.0(3.0)$ & $35.0(15.0)$ & $70.0(30.0)$ \\
\hline Import price of services & $5.5(5.5)$ & $27.5(27.5)$ & $55.0(55.0)$ \\
\hline
\end{tabular}

Import price shocks are equivalent to the import tariffs (without the revenues). ${ }^{25}$ Interpreting the export price shocks is less straightforward. They show loss of competitiveness of domestic goods relative to other exports to the EU. If the EU export market price is lower UK goods become less competitive. The $22 \%-40 \%$ of export price shocks in the FTA scenario are equivalent to a $28 \%$ -

\footnotetext{
${ }^{25}$ As was mentioned before non-tariff barriers constitute a larger part of trade restrictions and affect the real costs of trade.
} 
$67 \%^{26}$ UK export tariff (or EU import tariff). The $35 \%-40 \%$ of export price shocks in the WTO scenario are equivalent to a 54\%-67\% UK export tariff (or EU import tariff). Thus, tariff equivalent shocks are similar in magnitude to achieve comparable reductions in export and imports.

Throughout we assume zero net interregional and international migration. ${ }^{27}$

\section{Results}

We first report the results of the export and import price shocks reflecting the combined effects of tariff and non-tariff barriers created by Brexit. We then consider the likely impact of the net fiscal saving. The possible impacts of Brexit on migration flows are then discussed. Throughout we report real consumption and real government expenditure per capita as indicators of welfare.

The trade shocks

It is clear from Table 3 that FTA and WTO scenarios are qualitatively very similar; only the size of the price shocks differs. Not surprisingly, therefore, the results are qualitatively similar, differing only in terms of the scale of impacts. Here we concentrate primarily on the case of a hard Brexit (WTO), but note the impact of the "softer" exit (FTA) would be on key results. ${ }^{28}$

Leaving the EU triggers a combination of price changes that generate a range of complex responses, some of which are conflicting. It is easiest to understand its overall impact by first

\footnotetext{
${ }^{26}$ To calculate equivalent export tariff we divide domestic price in the base year (normalised to 1 ) by the resultant EU export price. For example, $1 /(1-0.22)=1.28$.

27 Figus et al (2017) consider possible migration responses.

${ }^{28}$ We report the full FTA results in Appendix A to Figus et al (2017).
} 
examining the impacts of export and import price changes separately. Table 4 summarises the results of applying only the export price shocks for the WTO scenario. All figures are expressed as percentage changes relative to the baseline and are reported for the short run, where capital stocks are fixed, five and ten years after the introduction of the shock, and for the long run, where capital stocks are fully adjusted and the economy has returned to a steady state equilibrium.

Table 4. WTO scenario applied only to export prices (\% changes relative to baseline)

\begin{tabular}{l|cccc|} 
& Sort Run & $\mathbf{5}$ years & $\mathbf{1 0}$ years & Long Run \\
\hline GDP & -0.0 & -0.5 & -1.6 & -3.0 \\
Total Exports & -0.6 & -3.2 & -6.7 & -8.3 \\
Exports of goods to the EU & -5.1 & -25.7 & -50.5 & -51.8 \\
Exports of services to the EU & -6.1 & -29.8 & -57.2 & -57.5 \\
Exports to non-EU & 1.8 & 9.0 & 17.5 & 16.1 \\
Exports to RUK & 0.0 & -0.3 & -1.4 & -3.2 \\
Total imports & -0.6 & -3.4 & -6.8 & -8.0 \\
Imports of goods from the EU & -1.5 & -7.3 & -13.8 & -14.3 \\
Imports of services from the EU & -1.6 & -8.3 & -15.6 & -16.4 \\
Imports from non-EU & -1.7 & -7.9 & -14.6 & -14.9 \\
Imports from RUK & 0.4 & 1.2 & 1.5 & -0.3 \\
CPI & -0.8 & -3.9 & -7.3 & -6.9 \\
Employment & -0.0 & -0.4 & -1.2 & -2.3 \\
Real wage & -0.0 & -0.7 & -1.8 & -3.1 \\
Consumption & -0.2 & -1.4 & -3.3 & -4.6 \\
Government expenditure & 0.4 & 1.5 & 2.0 & -0.3 \\
\hline
\end{tabular}

Source: simulation results

The imposition of the tariff (and tariff-equivalent-non-tariff barriers) on our exports to the EU reduces the competitiveness of UK goods within the EU and leads to a reduction in the price received by exporters and in the demand for those exports. The contraction in demand for UK produced goods leads to a reduction in economic activity and domestic prices and wages, with the 
latter pressures mitigating the contraction to a degree through improving competitiveness relative to ROW (Table 4). Initially this reflects excess capacity and falling rental rates, especially in export sectors, but the fall in demand for goods and services has a negative impact on the labour market. Employment falls, the unemployment rate rises, and real wages are pushed down, depressing consumption. CPI falls continuously and is $7.3 \%$ below the base value by period 10 . Improvement in competitiveness vis-a-vis ROW arising from the fall in prices leads to increases in exports to nonEU countries, which mitigates some of the negative effects. Capital stocks gradually contract until capacity is ultimately at its desired level, in each sector, in long-run equilibrium.

The introduction of tariff (and tariff-equivalent non-tariff barriers) on imports increases the domestic prices of imports and reduces the demand for them (Table 5). The import price shock induces a number of partially countervailing effects, reflecting imports' three uses as intermediate inputs, household consumption and investment goods. Consumption, investment and domestic prices all rise due to increased import prices. Intermediates exert the strongest impact because this adversely affects competitiveness and domestic (e.g., household consumption) as well as export demand, so economic activity declines. Table 5 shows that in this simulation under the WTO scenario domestic prices rise by $9.5 \%$ by year 10 and GDP and employment decline by $4.4 \%$ and $5.0 \%$ respectively over the same time period. This compares to the $1.6 \%$ and $1.2 \%$ falls in the same variable with the export price shock reported in Table 4.

It might seem counterintuitive that import restrictions would have a stronger negative impact on the economy. The populist view of protectionism is that it is likely to have significant benefits for the home economy. However, Caplan (2007) argues that this is an example of voter irrationality 
and an emotional, zero-sum attitude to trade and interaction in general with outsiders (foreigners). The results in Table 6 suggest that this view might have some traction.

Table 5. WTO scenario applied only to import prices (\% changes relative to baseline)

\begin{tabular}{l|cccc|} 
& $\begin{array}{c}\text { Sort } \\
\text { Run }\end{array}$ & $\mathbf{5}$ years & 10 years & Long Run \\
\hline GDP & -0.3 & -2.0 & -4.4 & -6.2 \\
Total Exports & -0.4 & -2.0 & -4.3 & -6.4 \\
Exports of goods to the EU & -2.1 & -8.4 & -14.1 & -15.5 \\
Exports of services to the EU & -0.9 & -5.1 & -10.2 & -12.2 \\
Exports to non-EU & -1.7 & -7.6 & -13.3 & -14.8 \\
Exports to RUK & 0.4 & 1.0 & 0.6 & -1.7 \\
Total imports & -1.9 & -7.3 & -12.0 & -13.2 \\
Imports of goods from the EU & -7.7 & -30.1 & -47.1 & -47.9 \\
Imports of services from the EU & -9.4 & -35.3 & -54.2 & -54.2 \\
Imports from non-EU & 2.2 & 10.9 & 19.8 & 19.3 \\
Imports from RUK & 0.2 & 0.5 & 0.0 & -2.0 \\
CPI & 1.0 & 5.1 & 9.5 & 10.4 \\
Employment & -0.5 & -2.5 & -5.0 & -6.4 \\
Real wage & -0.9 & -3.8 & -6.9 & -8.3 \\
Consumption & -0.8 & -3.3 & -5.9 & -7.2 \\
Government expenditure & -1.9 & -8.7 & -15.6 & -18.3 \\
\hline
\end{tabular}

Source: simulation results

Table 6: WTO scenario, applied only to imports for household consumption, with a fixed nominal wage (\% changes relative to baseline)

\begin{tabular}{l|cccc|} 
& Sort Run & $\mathbf{5}$ years & $\mathbf{1 0}$ years & Long Run \\
\hline GDP & -0.1 & -0.0 & 0.6 & 2.2 \\
Total Exports & -0.0 & 0.2 & 0.8 & 2.2 \\
Exports of goods to the EU & -0.3 & -1.0 & -1.2 & $\mathbf{0 . 0}$ \\
Exports of services to the EU & -0.2 & -0.9 & -1.2 & $-\mathbf{0 . 0}$ \\
Exports to non-EU & -0.3 & -0.9 & -1.2 & 0.0 \\
Exports to RUK & 0.1 & 0.8 & 1.9 & 3.4 \\
Total imports & -0.6 & -1.7 & -2.3 & -1.5 \\
Imports of goods from the EU & -1.2 & -4.1 & -5.9 & $-\mathbf{- 5 . 8}$ \\
Imports of services from the EU & -3.6 & -13.1 & -19.6 & $-\mathbf{1 9 . 1}$ \\
imports from RUK & 0.2 & 1.0 & 2.2 & 3.3 \\
Imports from non-EU & 0.2 & 1.3 & 2.4 & 2.8 \\
CPI & 0.4 & 1.8 & 2.9 & 2.3
\end{tabular}




\begin{tabular}{l|cccc|} 
Employment & -0.1 & -0.0 & 0.6 & 2.1 \\
Real wage & -0.4 & -1.8 & -2.9 & -2.3 \\
Consumption & -0.3 & -0.9 & -0.9 & 0.3 \\
Government expenditure & -0.8 & -2.8 & -3.7 & -1.5 \\
\hline
\end{tabular}

Source: simulation results

The simulation results reported in Table 6 provide a decomposition of the import price effect, to focus on the transmission mechanism through consumption. First, import prices are only increased for consumption goods and services. The prices of imported intermediates and investment goods are unaffected. Second, the nominal wage is held constant. Although we initially observe very small negative GDP and employment effects, by year 10 there is a $0.6 \%$ increase in GDP and employment. In this case there is no direct feed through from import restrictions to domestic product prices. Substitution by consumers away from imports (and international trade) to domestic goods and services (and interregional trade) stimulates domestic output. However, this positive effect comes at the cost of falling real wages, which decline by $2.9 \%$ by year 10 . Under the bargained real wage closure, the impact again becomes negative: even without the impact on intermediates, the adverse supply effect of the import price rise dominates the beneficial consumption effect on economic activity.

However, in fact, imports include intermediates and the import price rise imparts an adverse supply shock to the Scottish economy, reinforced where wages are determined in real terms so that, overall, increasing barriers to imports from the EU exacerbates the contraction in both regions.

These findings have interesting, and perhaps surprising policy implications. Outside of negotiations the UK has no influence over the export restrictions it will face after leaving the EU. However, import restrictions are, to some extent, under the control of the UK government. Even if WTO rules 
govern the level of tariffs imposed on imports of goods and services from the EU after Brexit, the UK can choose what type of controls to impose at the border. It can be argued that, if it so chooses, the UK government could allow continued open access for the EU imports in the UK market. In public debate protectionist measures are often thought to benefit the home (tariff-imposing) country. Our results suggest that this is not the case for the UK, at least as far as trade with the EU is concerned. Even if the EU does not grant the UK a preferential trade deal, adoption by the UK of a more lenient attitude towards EU imports would be in its own interests: "retaliation" here would be self-defeating, and exacerbate the scale of the contractions.

Of course, Brexit in fact involves the simultaneous implementation of both export and import price shocks, with the latter applying to all imports. Table 7 reports the overall Brexit results for the WTO scenario under our default model assumptions of a bargained real wage and no migration.

Table 7. WTO scenario, all price shocks applied (\% changes relative to baseline)

\begin{tabular}{l|cccc|c|} 
& Sort Run & $\mathbf{5}$ years & 10 years & Long Run & $\begin{array}{c}\text { RUK Long } \\
\text { Run }\end{array}$ \\
\hline GDP & -0.3 & -2.4 & -5.8 & -9.7 & -13.0 \\
Total Exports & -0.9 & -5.0 & -10.2 & -14.5 & -24.4 \\
Exports of goods to the EU & -7.0 & -32.0 & -57.6 & $-\mathbf{5 9 . 7}$ & $-\mathbf{6 0 . 6}$ \\
Exports of services to the EU & -6.9 & -33.4 & -61.7 & -63.2 & -60.5 \\
Exports to non-EU & 0.0 & 0.7 & 1.7 & -2.3 & 1.8 \\
Exports to RUK & 0.4 & 0.9 & -0.4 & -5.6 & -3.3 \\
Total imports & -2.5 & -9.9 & -16.5 & -19.5 & -35.6 \\
Imports of goods from the EU & -9.1 & -34.9 & -53.9 & -55.1 & -59.6 \\
Imports of services from the EU & -10.9 & -40.4 & -60.9 & -61.3 & -65.2 \\
Imports from non-EU & 0.5 & 2.4 & 3.1 & 1.9 & -62.4 \\
Imports from RUK & 0.6 & 1.9 & 1.9 & -3.3 & -5.6 \\
CPI & 0.2 & 0.9 & 1.4 & 3.2 & -0.3 \\
Employment & -0.5 & -2.8 & -5.9 & -9.2 & -12.5 \\
Real wage & -0.9 & -4.0 & -7.2 & -9.9 & -11.5 \\
Consumption & -0.9 & -4.4 & -8.2 & -11.1 & -14.6
\end{tabular}




\begin{tabular}{l|llll|l|} 
Government expenditure & -1.5 & -6.9 & -12.7 & -18.6 & -26.6 \\
\hline
\end{tabular}

Source: simulation results

The two types of trade shocks have countervailing effects on prices; here the upward pressure on prices from imports predominates. Combining the two shocks reinforces the negative effects of each on exports, GDP and employment, given the nature and scale of imports from the EU. Scotland does not now obtain the full benefit from the improvement in competitiveness vis-a-vis non-EU countries that it would enjoy if only export prices are affected.

As expected there are substantial contractions in real consumption and real wages, with rises in the CPI reflecting the net effect of increases in import prices and falls in export competitiveness in REU markets. ${ }^{29}$ After 10 years GDP is down nearly $6 \%$ in Scotland (and $7.4 \%$ in RUK). While the WTO results reported here reflect a worst case "no deal" scenario, the FTA simulation does suggest that although a softer Brexit would be associated with smaller impacts, these are still very substantial, with reductions in GDP of $4 \%$ in Scotland and $5 \%$ in RUK (by year 10 ). ${ }^{30}$

The benefits of using a multi-regional model can be seen by comparing the results presented above with a simulation which only applies shocks to Scotland. Between $17 \%$ and $18 \%$ of the long-run effect on GDP and employment is due to the spillovers from the RUK. Ignoring them by using a single-region model for simulations would significantly underestimate the negative effect of Brexit on Scotland.

\footnotetext{
${ }^{29}$ Recall that our default assumption is zero net migration, so that e.g. percentage changes in real consumption also indicate percentage changes in real consumption per capita; welfare declines in both Scotland and RUK (here and across all the trade simulations).

${ }^{30}$ For full FTA results see Appendix A to Figus et al (2017).
} 
Overall, we estimate the impacts of Brexit through trade to be rather more severe than the CGE analyses of PwC (2016) and Dhingra et al. (2017a). The first - and major - part of the explanation is simply the scale of the shock to trade flows following Brexit. We base this on Ebell (2016) because these are the best estimates of their kind, focussed explicitly on Brexit. Second, we have a model that allows adjustment to a long-run equilibrium in which all capital stocks are ultimately at their desired levels; it is clear from our simulations that the impact of Brexit typically increases with the time interval considered. Third our model has some features that are closer to conventional macro-economic models in capturing aspects of imperfect competition in the labour market, and in having investment independent of savings and driven by profitability. Estimates of Brexit impacts from conventional macroeconomic models tend to be greater than those from other CGE models. (HM Treasury, 2016). Fourth, we consider import as well as export price effects, whereas others have tended to focus only on exports (e.g. Ebell and Warren, 2016), perhaps on the basis that these are (at least to a much greater extent) under the influence of the UK Government. As we have seen, contrary to populist assertions, we find that "retaliation" with respect to our imports from the EU significantly reduces economic activity and welfare: indeed we find this to be even more important in governing the overall impact of Brexit than the impact on our exports to the EU.

\section{Fiscal effects}

Table 8 illustrates the effect of the fiscal stimulus that results from discontinuing the entire EU net fiscal contribution, and distributing the saving between Scotland and RUK on the basis of 
population shares. ${ }^{31}$ Of course, currently both the total net fiscal saving, and its distribution across regions are unknown.

Table 8: Fiscal effects: long-term (\% changes relative to baseline)

\begin{tabular}{l|cccc} 
& Sort Run & $\mathbf{5}$ years & $\mathbf{1 0}$ years & Long Run \\
\hline GDP & 0.2 & 0.2 & 0.2 & 0.1 \\
Total Exports & -0.7 & -0.8 & -0.9 & -0.9 \\
Exports of goods to the EU & -0.8 & -1.2 & -1.3 & -1.3 \\
Exports of services to the EU & -2.2 & -1.8 & -1.7 & -1.7 \\
Exports to RUK & -0.4 & -0.5 & -0.5 & -0.6 \\
Total imports & 1.1 & 0.7 & 0.7 & 0.7 \\
Imports of goods from the EU & 1.4 & 1.0 & 1.0 & 1.0 \\
Imports of services from the EU & 2.5 & 1.8 & 1.7 & 1.7 \\
Imports from RUK & 0.1 & 0.0 & -0.0 & -0.0 \\
CPI & 1.0 & 0.7 & 0.7 & 0.7 \\
Employment & 0.4 & 0.3 & 0.3 & 0.3 \\
Real wage & 0.7 & 0.6 & 0.5 & 0.5 \\
Consumption & 0.7 & 0.6 & 0.5 & 0.5 \\
Government consumption & 2.4 & 2.4 & 2.3 & 2.3 \\
\hline
\end{tabular}

Source: simulation results

Following the increase in public expenditure there is an increase in prices. This initially reflects both capacity constraints and increased real wages as employment increases, reducing the unemployment rate. Negative competitiveness effects arising from the price increases, however, dampen the positive stimulus. By year 10, GDP and employment have increased by $0.2 \%$ and $0.3 \%$

\footnotetext{
${ }^{31}$ For simplicity we assume that the government expenditures only impact initially on demand. If the expenditure has beneficial supply-side effects (e.g. spending on training) then these results underestimate the beneficial impact of the fiscal savings. However, recall that government expenditure is falling in all the analyses of the trade shocks; if that expenditure has supply-side effects our analysis underestimates the scale of the likely contraction. See e.g. Lecca et al (2017).
} 
respectively, and whilst public and household expenditure has increased, the positive demand effect is dampened by some crowding out of exports.

How reasonable are the assumptions on which the results of Table 8 are based? Since the UK Government is committed to maintaining gross EU expenditures, so that, for example, Scotland's greater share of agricultural subsidies would be maintained, at least initially, our assumption about the regional distribution of net fiscal savings seems a reasonable first approximation. However, the assumption that the whole of the current net fiscal transfer would be saved post Brexit is unrealistic except under the WTO scenario. However, as can be seen from the results in Table 8, the overall impacts of Brexit prove to be insensitive to any reasonable estimate of the scale of fiscal savings, given the extremely modest stimulus generated by what is the maximum possible fiscal saving. Accordingly, we do not pursue it further. ${ }^{32}$

Note that these are the effects of the fiscal stimulus in isolation. This simulation does not take into account the trade impacts set out above. Whilst there is a modest boost to the economy, this is much smaller, even in the best case scenario in which the UK saves its entire current net fiscal contribution, than the negative effects from reduced EU trade identified in Table 7.

\section{Combined effect of the trade shocks and fiscal effects}

Adding the fiscal stimulus (Table 8) to the trade effects (Table 7) leads to a slight reduction in the overall negative effects, but fiscal savings do not come close to offsetting the adverse trade effects of Brexit. Scottish GDP now falls by $5.6 \%$ by period 10 , rather than $5.8 \%$.

\footnotetext{
${ }^{32}$ A reviewer suggested that assumptions that the UK's fiscal contribution after leaving the EU could be based on the per capita contributions in the Norway or Switzerland cases. This would have only a negligible impact, however, on our overall results.
} 
Figure 2 provides a comparative analysis of various scenarios on GDP and Employment.

Figure 2. Long-run effects on employment and GDP, \% changes relative to baseline

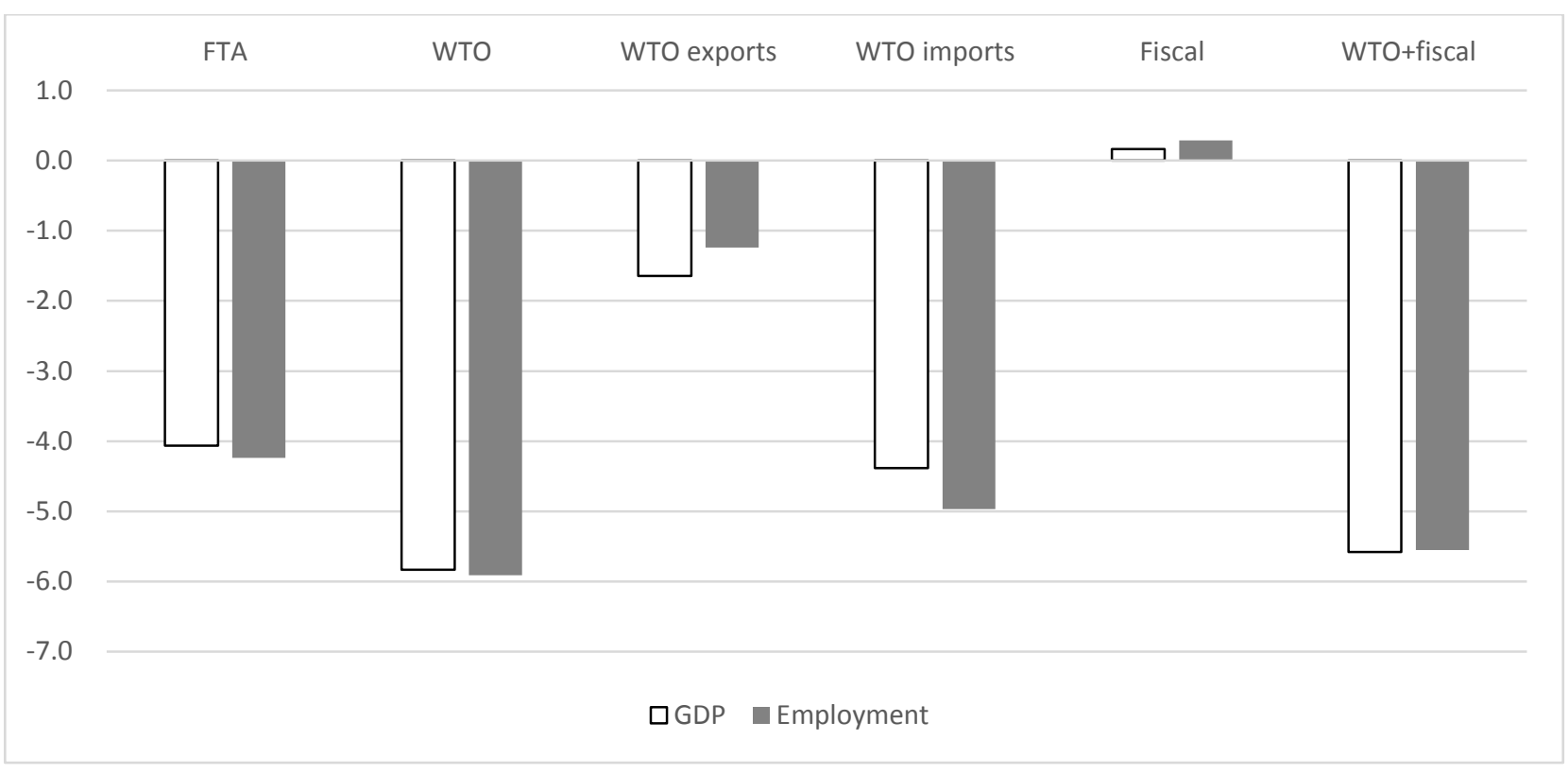

Source: simulation results

\section{Conclusions}

In this paper we explore the possible consequences of leaving the EU for the Scottish economy. There have been a number of studies of the impact on the UK macro-economy and some have calculated the regional impacts in a pro rata manner. However, ours is the first attempt to provide a system-wide analysis of Brexit impacts simultaneously on both the Scottish and RUK economies, which necessitates an explicitly interregional approach. Our results support that approach: we find that spillover effects from the RUK to Scotland are substantial, accounting for nearly one fifth of the overall impact of Brexit on Scottish GDP.

A number of general conclusions follow from our analysis of the likely impact of Brexit on the UK economy and its regions. First, withdrawal from the Single Market is, in the absence of significant 
new bilateral trade deals, unambiguously bad news for the UK economy as a whole and for both the Scottish and RUK economies, although rather worse news for the latter given its greater integration with the EU. These differential impacts suggest that the effects of leaving the EU will vary spatially across the UK. Scotland is in a favoured position concerning regional data, modelling and policy expertise. It should be a priority of the UK government to strengthen these resources and capabilities in all regions of the UK.

Second, the scale of the adverse impacts of Brexit on the Scottish and RUK economies depends on the precise trading arrangements that are negotiated. If no trade deal is secured and the WTO default position is adopted, the impact on trade flows alone could generate a loss of as much as nearly $6 \%$ of GDP after 10 years (if imports and exports are treated symmetrically). However, we find that a free trade agreement in these circumstances could limit the impact after 10 years to just over $4 \%$ of GDP. Brexit-related negotiations therefore really matter, in that they may significantly mitigate the adverse trade effects of leaving the Single Market.

Third, the adverse impacts of Brexit can be mitigated to a degree using the reduction in the net fiscal contribution to the EU to stimulate public spending in both Scotland and RUK. However, even in the most optimistic case, where the UK makes no continuing contribution to the EU under WTO scenario, the net fiscal contribution does not come close to compensating for the adverse impact on trade.

Fourth, UK policy may also matter in that it can directly influence elements of the trade barriers that affect imports. The populist view that it would be in our interest to raise tariff and non-tariff barriers on imports from the EU, especially when barriers are being imposed on our exports to the EU, is problematic. This would have a positive effect on the Scottish economy if imports were 
primarily for consumption and workers were willing to accept a cut in their real wage. However, in practice, imports of intermediate goods are important, so barriers to EU imports constitute an adverse supply shock to the Scottish economy that is exacerbated if, as in normal times, workers bargain for real wages. Our results suggest that the imposition of barriers to imports from the EU by the UK would be self-defeating, and in fact would simply add - possibly substantially - to the scale of the Brexit-induced contraction.

Fifth, our core estimates cannot be interpreted as reflecting a "worst case scenario". If, as HM Treasury and others believe, Brexit, through reducing the degree of openness of the UK economy, impacts adversely on productivity, further economic contraction would result. Similarly, given that Brexit makes both Scotland and RUK less attractive locations to live and work, since real wages and consumption per head will be lower and unemployment rates higher as a consequence, there will be an incentive for out-migration, which would further depress economic activity. However, we should sound a note of caution here in that these conclusions are predicated upon a ceteris paribus assumption, which implies that we do not consider, for example, possible new third country trade deals, or any other possible policy responses.

Future research should consider alternative scenarios as appropriate, perhaps extended, subject to data limitations, to the other regions of the UK, although retention of the interregional approach would be essential (and would include competing regions closest to Scotland). As negotiations proceed it may be possible to narrow the range of projected outcomes, once greater clarity is forthcoming about possible future trade relations, including the potential for trade deals with third countries. Clearly, however, successful trade negotiations, and indeed economic growth in the EU and the rest of the world, could mitigate, some of the impacts identified here. 


\section{References}

Armington PS (1969) A theory of demand for products distinguished by place of production. Staff Papers, 16(1), 159-78

Baier S, Bergstrand J, Egger P, McLaughlin P (2008) Do economic integration agreements actually work? Issues in understanding the causes and consequences of the growth in regionalism. The World Economy,.31(4), 461-97

Blanchflower GD, Oswald A J (1984) Estimating a Wage Curve for Britain. The Economic Journal, $104,1025-43$

Baldwin R and Venables A, (1995) Regional economic integration, ch. 31, p. 1597-1644 in Grossman, G. M. and Rogoff, K. eds., Handbook of International Economics, vol. 3, Elsevier Capital Economics (2016) The economic impact of 'Brexit'. Report prepared for Woodford Investment Management

Caplan B (2007) The Myth of the Rational Voter. Princeton University Press

Ceglowski J (2006) Does gravity matter in a service economy? Review of World Economics, vol. $142(2), 307-29$

Cicerone G, McCann P, and Venkhorst, V A (2017) The Continental Divide? Economic Exposure to Brexit in Regions and Countries on Both Sides of the Channel, paper presented at the British and Irish Regional Science Association (Harrogate) 
Dhingra S, Ottaviano G, Sampson T, Van Reenen J (2016a) The Consequences of Brexit for UK Trade and Living Standards. Centre for Economic Performance, CEPBREXITO2

Dhingra S, Ottaviano G, Sampson T, Van Reenen J (2016b) The Impact of Brexit on Foreign Investment in the UK. Centre for Economic Performance, CEPBREXIT03

Dhingra S, Huang H, Ottaviano G, Pessoa, P J, Sampson T, Van Reenen J (2017a) The Costs and Benefits of Leaving the EU: Trade Effects. Centre for Economic Performance Discussion Paper 1478

Dhingra S, Machin S, and Overmann H (2017b) The Local Economic Effects of Brexit, Centre for Economic Performance, CEPBREXIT10

Eaton, J. and Kortum, S. (2002), Technology, Geography, and Trade. Econometrica, 70, pp.17411779

Ebell M (2016) Assessing the Impact of Trade Agreements on Trade. National Institute Economic Review, No. 238, R31-42

Ebell M and Warren J (2016) The Long-Term Economic Impact of Leaving the EU. National Institute Economic Review, Issue 236

Economists for Brexit (2016) The Economy After Brexit. EFB report

Egger P, Larch M, Staub KE, Winkelmann R (2011) The trade effects of endogenous preferential trade agreements. American Economic Journal: Economic Policy, 3(3), 113-143

Evans CL (2001) Home Bias in Trade: Location or Foreign-ness? FRB of New York Staff Report No. 128 
Figus, G, Lisenkova, K, McGregor, P G, Roy, G and Swales, J K (2017) “The long-term economic implications of Brexit for Scotland: an interregional analysis", Strathclyde Discussion Papers in Economics, No. $17-11$

Gibson H (1990) Export Competitiveness and UK Sales of Scottish Manufacturers. Working Paper, Scottish Enterprise, Glasgow

Harris R (1989) The Growth and Structure of the UK Regional Economy. 1963-1985. Aldershot

HM Treasury (2016a) The long-term economic impact of EU membership and the alternatives. HM Treasury report

HM Treasury (2016b) The immediate economic impact of leaving the EU. HM Treasury report Layard R, Nickell S, Jackman R (1991) Unemployment: Macroeconomic Performance and the Labour Market. Oxford University Press, Oxford

Lecca P, McGregor PG, and Swales JK (2015) “Scotland - no detriment, no danger; the interregional impact of a balanced budget regional fiscal expansion": IPPI Discussion Paper.

Lecca P, McGregor PG, and Swales JK (2017) “Taxes and spending”, Chapter 2 in. Keating, M. (ed.) A Wealthier, Fairer Scotland: The political economy of constitutional change, 26-54. Edinburgh: Edinburgh University Press

Langella M, and Manning A (2016) Who voted Leave?, CentrePiece - The Magazine for Economic Performance, Centre for Economic Performance, LSE

Lisenkova K and Sanchez-Martinez M (2016) The Long-Term Macroeconomic Effects of Lower Migration to the UK. NIESR Discussion Paper No. 460 
Los B, McCann P, Springford J, Thissen M (2017) The mismatch between local voting and the local economic consequences of Brexit. Regional Studies, 51(5), 786-799

McCallum J (1995) National borders matter: Canada-US regional trade patterns. The American Economic Review, 85(3), 615-623

OECD (2016) The Economic Consequences of Brexit: A Taxing Decision. OECD Economic Policy Paper. April 2016 No. 16

Oxford Economics (2016) Assessing the Economic Implications of Brexit. Report

PWC (2016) Leaving the EU: Implications for the UK Economy. Report prepared for the CBI

Sheffield Political Economy Research Institute (2016) UK regions and UK structural and investment funds. SPERI British Political Economy Brief No. 24, Sheffield, SPERI

Springford J, McCann P, Los B, Thissen M (2016) Brexiting yourself in the foot: why Britain's Eurosceptic regions have most to lose from EU withdrawal. Insight, Centre for European Reform, London

WTO (2016) World Trade Profiles. WTO, Geneva 
Appendix. Complete model listing. Prices

$$
\begin{aligned}
& P M E U_{r, i, t}={\overline{P M E U_{r, i}}} \\
& P M W_{r, i, t}=\overline{P M W}_{r, i} \\
& P M_{r, i, t} \cdot \sum_{j} V M_{r, i, j, t}={\overline{P M W_{r, i}}} \cdot \sum_{j} V M W_{r, i, j, t}+\overline{P M E U}_{r, i} \cdot \sum_{j} V M E U_{r, i, j, t} \\
& P E_{r, i, t}=\overline{P E}_{r, i} \\
& P E U_{r, i, t}=\overline{P E U}_{r, i} \\
& P I_{r, i, t}=P Q_{r, i, t} \\
& P Q_{r, i, t}=\frac{P R_{r, i, t} \cdot R_{r, i, t}+P I_{r, i, t} \cdot M V I_{r, i, t}+P M_{i, t} \cdot M_{i, t}}{R_{r, i, t}+M V I_{r, i, t}+M_{r, i, t}} \\
& P I R_{r, j, t}=\frac{\sum_{i} V R_{r, i, j, t} \cdot P R_{r, j, t}+\sum_{i} V I_{r, i, j, t} \cdot P I_{r, i, t}}{\sum_{i} V I R_{i, j, t}} \\
& P Y_{r, j, t} \cdot a_{r, j}^{Y}=\left(P R_{r, j, t} \cdot\left(1-b t a x_{r, j}-s u b_{r, j}-d e p_{r, j}\right)-\sum_{i} a_{r, i, j}^{V} P Q_{r, j, t}\right) \\
& U C K_{r, t}=P k_{r, t} \cdot\left(r_{r}+\delta_{r}\right) \\
& P c_{r, t}^{1-\sigma^{c}}=\sum_{j} \delta_{r, j}^{f} \cdot P Q_{r, j, t}^{1-\sigma^{c}} \\
& P g_{r, t}^{1-\sigma^{g}}=\sum_{j} \delta_{r, j}^{g} \cdot P Q_{r, j, t}^{1-\sigma^{g}} \\
& P v_{r, t}^{1-\rho}=\sum_{i} \sum_{j} a_{r, i, j}^{V} \cdot P Q_{r, i, t}^{1-\rho} \\
& w_{r, t}^{b}=\frac{w_{r, t}}{\left(1+\tau_{r, t}\right)}
\end{aligned}
$$




$$
\begin{gathered}
\ln \left(\frac{w_{r, t}^{b}}{c p i_{r, t}}\right)=b_{r}-0.113 \ln \left(u_{r, t}\right) \\
r k_{r, j, t}=P Y_{r, j, t} \cdot \delta_{r, j}^{k} \cdot A_{r}^{Y \varrho_{j}} \cdot\left(\frac{Y_{r, j, t}}{K_{r, j, t}}\right)^{1-\varrho_{j}} \\
P k_{r, t}=\frac{\sum_{j} P Q_{r, j, t} \cdot \sum_{i} K M_{r, i, j}}{\sum_{i} \sum_{j} K M_{r, i, j}}
\end{gathered}
$$

\section{Production technology}

$$
\begin{gathered}
X_{r, i, t}=A_{r}^{X} \cdot\left[\delta_{r, i}^{Y} \cdot Y_{r, i, t}^{\rho_{i}^{X}}+\delta_{r, i}^{V} \cdot L_{r, i, t}^{\rho_{i}^{X}}\right]^{\frac{1}{\rho_{i}^{X}}} \\
Y_{r, j, t}=\left(A_{r}^{X}{ }_{r}^{\rho_{j}^{X}} \cdot \delta_{r, j}^{Y} \cdot \frac{P Q_{r, j, t}}{P Y_{r, j, t}}\right)^{\frac{1}{1-\rho_{j}^{X}}} \cdot X_{r, j, t} \\
V_{r, j, t}=\left(A_{r}^{X}{ }_{\rho_{j}^{X}}^{X} \cdot \delta_{r, j}^{V} \cdot \frac{P Q_{r, j, t}}{P v_{r, j, t}}\right)^{\frac{1}{1-\rho_{j}^{X}}} \cdot X_{r, j, t} \\
V V_{r, i, j, t}=a_{r, i, j}^{V} \cdot V_{r, i, t} \\
Y_{r, i, t}=A_{r}^{Y} \cdot\left[\delta_{r, i}^{k} \cdot K_{r, i, t}^{\rho_{i}^{Y}}+\delta_{r, i}^{l} \cdot L_{r, i, t}^{\rho_{i}^{Y}}\right]^{\frac{1}{\rho_{i}^{Y}}} \\
L_{r, j, t}=\left(A_{r}^{Y}{ }_{r}^{Y} \cdot \delta_{r, j}^{l} \cdot \frac{P Y_{r, j, t}}{w_{r, t}}\right)^{\frac{1}{1-\rho_{j}^{Y}} \cdot Y_{r, j, t}}
\end{gathered}
$$

\section{Trade}

$$
\begin{gathered}
V V_{r, i, j, t}=\gamma_{r, i, j}^{v v} \cdot\left[\delta_{r, i, j}^{v m} V M_{r, i, t}^{\rho_{i}^{A}}+\delta_{r, i, j}^{v i r} V I R_{r, i, t}^{\rho_{i}^{A}}\right]^{\frac{1}{\rho_{i}^{A}}} \\
\frac{V M_{r, i, j, t}}{V I R_{r, i, j, t}}=\left[\left(\frac{\delta_{r, i, j}^{v m}}{\delta_{r, i, j}^{v i r}}\right) \cdot\left(\frac{P I R_{r, i, t}}{P M_{r, i}}\right)\right]^{\frac{1}{1-\rho_{i}^{A}}} \\
V M_{r, i, j, t}=\gamma_{r, i, j}^{v m} \cdot\left[\delta_{r, i, j}^{v m e u} V M E U_{r, i, t}^{\rho_{i}^{A}}+\delta_{r, i, j}^{v m w} V M W_{r, i, t}^{\rho_{i}^{A}}\right]^{\frac{1}{\rho_{i}^{A}}}
\end{gathered}
$$




$$
\begin{aligned}
& \frac{V M E U_{r, i, j, t}}{V M W_{r, i, j, t}}=\left[\left(\frac{\delta_{r, i, j}^{v m e u}}{\delta_{r, i, j}^{v m w}}\right) \cdot\left(\frac{P M W_{r, i, t}}{P M E U_{r, i}}\right)\right]^{\frac{1}{1-\rho_{i}^{A}}} \\
& V I R_{r, i, j, t}=\gamma_{r, i, j}^{v i r} \cdot\left[\delta_{r, i, j}^{v i} V I_{r, i, t}^{\rho_{i}^{A}}+\delta_{r, i, j}^{v r} V R_{r, i, t}^{\rho_{i}^{A}}\right]^{\frac{1}{\rho_{i}^{A}}} \\
& \frac{V R_{r, i, j, t}}{V I_{r, i, j, t}}=\left[\left(\frac{\delta_{r, i, j}^{v r}}{\delta_{r, i, j}^{v i}}\right) \cdot\left(\frac{P I_{r, i, t}}{P R_{r, i, t}}\right)\right]^{\frac{1}{1-\rho_{i}^{A}}} \\
& E_{-} R E U_{r, i, t}={\overline{E \_} R E U_{i}}_{i} \cdot\left(\frac{P E U_{r, i}}{P R_{r, i, t}}\right)^{\sigma_{i}^{x}} \\
& E_{-} R N E U_{r, i, t}={\overline{E \_} R N E U_{i}}_{i} \cdot\left(\frac{P E_{r, i}}{P R_{r, i, t}}\right)^{\sigma_{i}^{x}} \\
& E_{-} I N T E R_{r, i, t}=M V I_{r^{\prime}, i, t} \\
& E_{-} I N T E R_{r, i, t}+E_{-} R E U_{r, i, t}+E_{-} R N E U_{r, i, t}=E_{r, i, t}
\end{aligned}
$$

\section{Regional Demand}

$$
R_{r, i, t}=\sum_{j} V R_{r, i, j, t}+Q H R_{r, i, t}+Q V R_{r, i, t}+Q G R_{r, i, t}
$$

\section{Total Production}

$$
X_{r, i, t}+M_{r, i, t}=\sum_{j} V V_{r, i, j, t}+Q H_{r, i, t}+Q V_{r, i, t}+Q G_{r, i, t}+E_{r, i, t}
$$

\section{Households and other Domestic Institutions}

$$
\begin{gathered}
Y H_{r, t}=\left(1-\tau_{r, t}\right) L_{r, t}^{S}\left(1-u_{r, t}\right) w_{r, t}+T R F_{r, t}+\Pi_{r, t} \\
\operatorname{Tr} f_{r, t}=P C_{r, t} \cdot \overline{\operatorname{Trf}} \\
\Pi_{r, t}=d_{r}^{h} \cdot \sum_{i} r k_{r, i, t} K_{r, i, t}
\end{gathered}
$$




$$
\begin{aligned}
& S_{r, t}=m p s_{r} \cdot Y H_{r, t} \\
& C_{r, t}=Y H_{r, t}-S_{r, t} \\
& Q H_{r, i, t}=\delta_{r, i}^{f} \rho_{i}^{c} \cdot\left(\frac{P c_{r, t}}{P Q_{r, i, t}}\right)^{\rho_{i}^{c}} \cdot C_{r, t} \\
& Q H_{r, i, t}=\gamma_{r, i}^{f} \cdot\left[\delta_{r, i}^{h i r} \cdot Q H I R_{r, i, t}^{\rho_{i}^{A}}+\delta_{r, i}^{h m} \cdot Q H M_{r, i, t}^{\rho_{i}^{A}}\right]^{\frac{1}{\rho_{i}^{A}}} \\
& \frac{Q H I R_{r, i, t}}{Q H M_{r, i, t}}=\left[\left(\frac{\delta_{r, i}^{h i r}}{\delta_{r, i}^{h m}}\right) \cdot\left(\frac{P M_{i}}{P I R_{r, i, t}}\right)\right]^{\frac{1}{1-\rho_{i}^{A}}} \\
& Q H M_{r, i, t}=\gamma_{r, i}^{f} \cdot\left[\delta_{r, i}^{h m e u} \cdot Q H M E U_{r, i, t}^{\rho_{i}^{A}}+\delta_{r, i}^{h m w} \cdot Q H M W_{r, i, t}^{\rho_{i}^{A}}\right]^{\frac{1}{\rho_{i}^{A}}} \\
& \frac{Q H M E U_{r, i, t}}{Q H M W_{r, i, t}}=\left[\left(\frac{\delta_{r, i}^{h m e u}}{\delta_{r, i}^{h m w}}\right) \cdot\left(\frac{P M W_{i}}{P M E U_{r, i, t}}\right)\right]^{\frac{1}{1-\rho_{i}^{A}}} \\
& Q H I R_{r, i, t}=\gamma_{r, i}^{f i r} \cdot\left[\delta_{r, i}^{h r} \cdot Q H R_{r, i, t}^{\rho_{i}^{A}}+\delta_{r, i}^{h i} \cdot Q H I_{r, i, t}^{\rho_{i}^{A}}\right]^{\frac{1}{\rho_{i}^{A}}} \\
& \frac{Q H R_{r, i, t}}{Q H I_{r, i, t}}=\left[\left(\frac{\delta_{r, i}^{h r}}{\delta_{r, i}^{h i}}\right) \cdot\left(\frac{P I_{r, i, t}}{P R_{r, i, t}}\right)\right]^{\frac{1}{1-\rho_{i}^{A}}}
\end{aligned}
$$

\section{Government}

$$
\begin{gathered}
F D_{r, t}=G_{r, t} P g_{r, t}+\sum_{d n g i n s} T R G_{d n g i n s, r, t} \cdot P c_{r, t} \\
-\left(d_{r}^{g} \cdot \sum_{i} r k_{r, i, t} \cdot K_{r, i, t}+\sum_{i} I B T_{r, i, t}+\tau_{r, t} \cdot \sum_{j} L_{r, j, t} \cdot w_{r, t}+\overline{F E_{r}} \cdot \varepsilon_{r, t}\right) \\
Q G_{r, i, t}=\delta_{r, i}^{g} \cdot G_{r, t} \\
Q G R_{r, i, t}=Q G_{r, i, t} ; Q G M_{r, i, t}=0
\end{gathered}
$$




\section{Investment Demand}

$$
\begin{aligned}
& Q V_{r, i, t}=\sum_{j} K M_{r, i, j} \cdot J_{r, j, t} \\
& Q V_{r, i, t}=\gamma_{r, i}^{v} \cdot\left[\delta_{r, i}^{q v m} \cdot Q V M_{r, i, t}^{\rho_{i}^{A}}+\delta_{r, i}^{q v i r} \cdot Q V I R_{r, i, t}^{\rho_{i}^{A}}\right]^{\frac{1}{\rho_{i}^{A}}} \\
& \frac{Q V M_{r, i, t}}{Q V I R_{r, i, t}}=\left[\left(\frac{\delta_{r, i}^{q v m}}{\delta_{r, i}^{q v i r}}\right) \cdot\left(\frac{P I R_{r, i, t}}{P M_{r, i}}\right)\right]^{\frac{1}{1-\rho_{i}^{A}}} \\
& Q V M_{r, i, t}=\gamma_{r, i}^{v} \cdot\left[\delta_{r, i}^{q v m e u} \cdot Q V M E U_{r, i, t}^{\rho_{i}^{A}}+\delta_{r, i}^{q v m w} \cdot Q V M W_{r, i, t}^{\rho_{i}^{A}}\right]^{\frac{1}{\rho_{i}^{A}}} \\
& \frac{Q V M E U_{r, i, t}}{Q V M W_{r, i, t}}=\left[\left(\frac{\delta_{r, i}^{q v m e u}}{\delta_{r, i}^{q v m w}}\right) \cdot\left(\frac{P M W_{r, i, t}}{P M E U_{r, i}}\right)\right]^{\frac{1}{1-\rho_{i}^{A}}} \\
& Q V I R_{r, i, t}=\gamma_{r, i}^{v i r} \cdot\left[\delta_{r, i}^{q v i} \cdot Q V I_{r, i, t}^{\rho_{i}^{A}}+\delta_{r, i}^{q v r} \cdot Q V R_{r, i, t}^{\rho_{i}^{A}}\right]^{\frac{1}{\rho_{i}^{A}}} \\
& \frac{Q V R_{r, i, t}}{Q V I_{r, i, t}}=\left[\left(\frac{\delta_{r, i}^{q v r}}{\delta_{r, i}^{q v i}}\right) \cdot\left(\frac{P I_{r, i, t}}{P R_{r, i, t}}\right)\right]^{\frac{1}{1-\rho_{i}^{A}}}
\end{aligned}
$$

Time path of investment

$$
\begin{gathered}
I_{r, i, t}=v \cdot\left(K S_{r, i, t}^{*}-K S_{r, i, t}\right) \cdot \delta K S_{r, i, t} \\
K S_{r, i, t}^{*}=\left(A_{r}^{Y} \rho_{j}^{Y} \cdot \delta_{r, j}^{k} \cdot \frac{P Y_{r, j, t}}{r k_{r, j, t}}\right)^{\frac{1}{1-\rho_{j}^{Y}}} \cdot Y_{r, j, t}
\end{gathered}
$$

Factors accumulation

$$
\begin{gathered}
K S_{r, i, t+1}=\left(1-\delta_{r}\right) \cdot K S_{r, i, t}+I_{r, i, t} \\
L S_{r, t}=\overline{L S}_{r}
\end{gathered}
$$




$$
\begin{gathered}
K_{r, i, t}=K S_{r, i, t} \\
L S_{r, t} \cdot\left(1-u_{r, t}\right)=\sum_{j} L_{r, j, t}
\end{gathered}
$$

Indirect taxes and subsidies

$$
I B T_{i, t}=\operatorname{btax}_{i} \cdot X_{i, t} \cdot P Q_{i, t}
$$

Total demand for import and current account

$$
\begin{gathered}
M_{r, i, t}=\sum_{j} V I_{r, i, j, t}+\sum_{j} V M_{r, i, j, t}+Q H M_{r, i, t}+Q G M_{r, i, t}+Q V I_{r, i, t}+Q V M_{r, i, t} \\
T B_{r, t}=\sum_{i} M_{r, i, t} \cdot P M_{r, i}-\sum_{i} E_{r, i, t} \cdot P E_{r, i, t}+\varepsilon \cdot\left(R E M_{r}+F E_{r}\right)
\end{gathered}
$$

Assets

$$
\begin{gathered}
V F_{r, i, t}=\lambda_{r, i, t} \cdot K_{r, i, t} \\
D_{r, t+1}=\left(1+r_{r}\right) \cdot D_{r, t}+T B_{r, t} \\
P g_{r, t+1} \cdot G D_{r, t+1}=\left[1+r_{r}+\left(\frac{P c_{r, t+1}}{P c_{r, t}}-1\right)\right] \cdot G D_{r, t} \cdot P g_{r, t}+F D_{r, t}
\end{gathered}
$$

\section{Steady State conditions}

$$
\begin{gathered}
\delta_{r} \cdot K S_{r, i, T}=I_{r, i, T} \\
R_{r, i, T}^{k}=\lambda_{r, i, T}\left(r_{r}+\delta_{r}\right) \\
F D_{r, T}=-\left[r_{r}+\left(\frac{P c_{r, t+1}}{P c_{r, t}}-1\right)\right] \cdot P g_{r, T} \cdot G D_{r, T}
\end{gathered}
$$




$$
\begin{gathered}
T B_{r, T}=-r \cdot D_{r, T} \\
N F W_{t} r=\left(1-\tau_{t}\right) L_{t}^{s}\left(1-u_{t}\right) w_{t}+\operatorname{Tr} f_{t} \\
F W_{r, t} \cdot r_{r, T}=\Pi_{r, t}-S_{r, t}
\end{gathered}
$$

\section{Glossary}
$i, j \quad(i=j)$
the set of goods or industries
$r, r^{\prime} \quad\left(r=r^{\prime}\right)$
the set of regions

$\begin{array}{ll}\text { Prices } & \\ P Y_{r, i, t} & \text { value added price } \\ P R_{r, i, t} & \text { regional price } \\ P Q_{r, i, t} & \text { output price } \\ P I R_{r, i, t} & \text { national commodity price (regional + RUK) } \\ P I_{r, i, t} & \text { price of RUK commodities } \\ P M_{r, i, t} & \text { price of ROW commodities } \\ P M E U_{r, i, t} & \text { price of REU commodities } \\ P M W_{r, i, t} & \text { price of non-EU commodities } \\ P E_{r, i, t} & \text { price of non-EU exports } \\ P E U_{r, i, t} & \text { price of REU exports } \\ r k_{r, i, t} & \text { rate of return to capital } \\ w_{r, t} & \text { unified nominal wage } \\ w_{r, t}^{b} & \text { after tax wage } \\ P k_{r, t} & \text { capital good price } \\ U C K_{r, t} & \text { user cost of capital }\end{array}$




$\begin{array}{ll}\lambda_{r, i, t} & \text { shadow price of capital } \\ P c_{r, t} & \text { aggregate consumption price } \\ P g_{r, t} & \text { aggregate price of Government consumption goods } \\ \varepsilon & \text { exchange rate [fixed] }\end{array}$

\section{Endogenous variables}

$X_{r, i, t}$

$R_{r, i, t}$

$M_{r, i, t}$

$E_{r, i, t}$

$E_{-} R E U_{r, i, t}$

$E_{\_} R N E U_{r, i, t}$

$Y_{r, i, t}$

$L_{r, i, t}$

$K_{r, i, t}$

$K S_{r, i, t}$

$L S_{r, i, t}$

$V V_{r, i, j, t}$

$V_{r, i, t}$

$V R_{r, i, j, t}$

$V M_{r, i, j, t}$

$V M E U_{r, i, j, t}$

$V M W_{r, i, j, t}$

$V I R_{r, i, j, t}$

$V I_{r, i, j, t}$ total output

regional supply

total import

total export (interregional + international)

export to REU

export to non-EU

value added

labour demand

physical capital demand

capital stock

labour supply

total intermediate inputs in $i$ and $j$

Total intermediate inputs in $i$

regional intermediate inputs

ROW intermediate inputs

REU intermediate inputs

Non-EU intermediate inputs

national intermediate inputs (ROW + RUK)

RUK intermediate inputs 


\begin{tabular}{|c|c|}
\hline$G_{r, i, t}$ & aggregate government expenditure \\
\hline$Q G_{r, i, t}$ & total government expenditure by sector $i$ \\
\hline$Q G R_{r, i, t}$ & regional government expenditure \\
\hline$Q G M_{r, i, t}$ & government expenditure( RUK + ROW) \\
\hline$C_{r, t}$ & aggregated household consumption \\
\hline$Q H_{r, i, t}$ & total households consumption in sector $i$ \\
\hline$Q H R_{r, i, t}$ & regional consumption in sector $i$ \\
\hline$Q H I R_{r, i, t}$ & regional + RUK consumption in sector $i$ \\
\hline$Q H M_{r, i, t}$ & ROW import consumption in sector $i$ \\
\hline$Q H M E U_{r, i, t}$ & REU import consumption in sector $i$ \\
\hline$Q H M W_{r, i, t}$ & Non-EU import consumption in sector $i$ \\
\hline$Q V_{r, i, t}$ & total investment by sector of origin $i$ \\
\hline$Q V R_{r, i, t}$ & regional investment by sector of origin $i$ \\
\hline$Q V M_{r, i, t}$ & ROW investment demand \\
\hline$Q V M E U_{r, i, t}$ & REU investment demand \\
\hline$Q V M W_{r, i, t}$ & Non-EU investment demand \\
\hline$Q V I R_{r, i, t}$ & national investment (regional + RUK) \\
\hline$Q V I_{r, i, t}$ & RUK investment demand \\
\hline$I_{r, j, t}$ & investment by sector of destination $j$ \\
\hline$J_{r, j, t}$ & investment by destination $j$ with adjustment cost \\
\hline$u_{r, t}$ & regional unemployment rate \\
\hline$R_{r, i, t}^{k}$ & marginal net revenue of capital \\
\hline$S_{r, t}$ & domestic non-government saving \\
\hline $\operatorname{Tr} f_{r, t}$ & households net transfer \\
\hline
\end{tabular}


$Y H_{r, t}$

$T B_{r, t}$

Exogenous variables

$\begin{array}{ll}\overline{R E M}_{r, t} & \text { remittances for Household } \\ \overline{F E}_{r, t} & \text { remittances for the Government } \\ G S A V_{r, t} & \text { government saving } \\ r_{r} & \text { interest rate }\end{array}$

\section{Elasticities}

$\sigma$

$\rho_{i}^{X}$

$\rho_{i}^{Y}$

$\rho_{i}^{A}$

$\sigma_{i}^{x}$

Parameters

$a_{r, i, j}^{V}$

$a_{r, j}^{Y}$

$\delta_{r, j}^{Y, V}$

$\delta_{r, j}^{k, l}$

$\delta_{r, i, j}^{v i r, v m, v r, v i}$

$\delta_{r, i, j}^{q v i r, q v m, q v r, q v i}$

$\delta_{r, i, h}^{h r, h m}$

$\delta_{r, i}^{g r, g m}$
Household income

current account balance

constant elasticity of marginal utility

elasticity between intermediate inputs and value added

elasticity between capital and labour

elasticity in Armington function

elasticity of export with respect to terms of trade

Input-output coefficients for $i$ used in $j$

share of value added on production

shares in CES output function in sector $j$

shares in value added function in sector $j$

shares parameters in CES function for intermediate goods

shares parameters in CES function for investment goods

shares parameters in CES function for households consumption

shares parameters in CES function for government consumption 


$\begin{array}{ll}\gamma_{r, i, j}^{v v, v i r} & \text { shift parameter in CES functions for intermediate goods } \\ \gamma_{r, i}^{f} & \text { shift parameter in CES function for households consumption goods } \\ \gamma_{r, i}^{g} & \text { shift parameter in CES function for government consumption } \\ b t a x_{r, i} & \text { rate of business tax } \\ K M_{r, i, j} & \text { physical capital matrix } \\ m p s_{r} & \text { rate of saving } \\ \tau_{r} & \text { rate of income tax } \\ \rho & \text { pure rate of consumer time preference } \\ b b_{r} & \text { rate of distortion or incentive to investment } \\ \delta_{r} & \text { rate of depreciation }\end{array}$

